University of Nebraska - Lincoln

DigitalCommons@University of Nebraska - Lincoln

Agronomy \& Horticulture -- Faculty Publications

Agronomy and Horticulture Department

1993

\title{
Breeding Systems for Cross-Pollinated Perennial Grasses
}

\author{
K. P. Vogel \\ University of Nebraska-Lincoln, kvogel1@unl.edu \\ Jeffrey F. Pedersen \\ University of Nebraska-Lincoln, jpedersen1@unl.edu
}

Follow this and additional works at: https://digitalcommons.unl.edu/agronomyfacpub

Part of the Agricultural Science Commons, Agriculture Commons, Agronomy and Crop Sciences Commons, Botany Commons, Horticulture Commons, Other Plant Sciences Commons, and the Plant Biology Commons

Vogel, K. P. and Pedersen, Jeffrey F., "Breeding Systems for Cross-Pollinated Perennial Grasses" (1993). Agronomy \& Horticulture -- Faculty Publications. 948.

https://digitalcommons.unl.edu/agronomyfacpub/948

This Article is brought to you for free and open access by the Agronomy and Horticulture Department at DigitalCommons@University of Nebraska - Lincoln. It has been accepted for inclusion in Agronomy \& Horticulture -Faculty Publications by an authorized administrator of DigitalCommons@University of Nebraska - Lincoln. 


\title{
Edited by Jules Janick
}

Copyright (c) by John Wiley \& Sons, Inc.

\section{Breeding Systems for}

\section{Cross-Pollinated Perennial Grasses}

\author{
K.P. Vogel and J.F. Pedersen
}

U.S. Department of Agriculture, Agricultural Research Service, 344

Keim, University of Nebraska, Lincoln, Nebraska 68583-0937

I. Introduction

II. Reproductive and Breeding Characteristics

III. Breeding Systems
A. Ecotype Selection
B. Recurrent, Restricted Phenotypic Selection
C. Half-sib Progeny Test
D. Between and Within Family Selection
E. Recurrent Multistep Family Selection

IV. Gains From Selection
A. Time Interval per Cycle
B. Potential Gain per Cycle
C. Potential Inbreeding per Cycle

V. Polycrossing

VI. Hybrid Cultivars

VII. Conclusions

Literature Cited

\section{INTRODUCTION}

The objectives of this review are to describe and critically evaluate breeding methods that have been developed for breeding improved, perennial cross-pollinated forage grasses. Previous reviews and book chapters on grass or forage crop breeding (Asay et al. 1979; Poehlman 1987; Sleper 1987; Wilkins 1991) have lacked rigorous quantitative genetic analyses of the relative advantages and disadvantages of the various breeding methods. Comparisons among breeding methods applicable to cross-pollinated plants are available (Fehr 1987; Empig et al. 1972; Hallauer and Miranda 1981; Nyquist 1991), but they are usually discussed in relation to annual grain crops. In addition to critiquing previously described breeding methods, we also describe a new breeding system that we are currently evaluating. 
K. P. YOGEL ANP I. F PEDERSEN

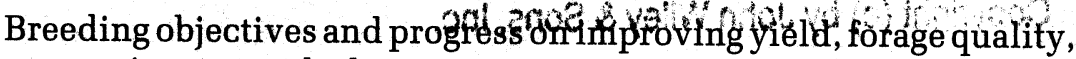
disease resistance, and other traits were addressed previously (Asay et al. 1979; Poehlman 1987; Sleper 1987; Barker and Kalton 1989; Burton 1989a; Meyer and Funk 1989; Vogel et al. 1989). Specific breeding techniques for making controlled crosses were described in recent reviews by Burson (1980) and Hovin (1980) and will not be addressed. Most important agronomic traits of forage grasses are quantitatively inherited. Breeding methods to improve these traits will be described and compared in terms of efficiency and effectiveness.

\section{REPRODUCTIVE AND BREEDINGCHARACTERISTICS}

Breeding systems that can be used effectively to improve a species are determined more by a specie s mode of reproduction than by any other factor (Allard 1960). Most perennial forage grasses reproduce either sexually via cross-pollination or by apomixis (Hanson and Carnahan 1956; Poehlman 1987). Only a few minor forage grasses including slender wheatgrass [Elymus trachycaulus (Link) Gould ex. Shinn.] and California bromegrass [Bromus carinatus Hook. \& Arn.] reproduce sexually by self-pollination (Hanson and Carnahan 1956). Currently, breeding emphasis on self-pollinated perennial grasses is minimal, and the breeding systems being utilization are adapted from small grain breeding systems for self-pollinated crops such as wheat [Triticum aestivum L.].

Many of the grasses that reproduce apomictically originate either in tropical or subtropical regions. A temperate exception is Kentucky bluegrass [Poa pratensis L.], which is also highly apomictic. Breeding methods for these grasses were reviewed by Bashaw and Funk (1987) and Hanna and Bashaw (1987). Breeding systems for improving apomictic species are unique and generally are not useful for improving sexual species.

Most important perennial forage and turf grasses used in the temperate regions of the world are cross-pollinated perennial grasses. These include tall fescue [Festuca arundinaceae Schreb.], smooth bromegrass [Bromus inermis Leyss.], wheatgrasses [Agropyron \& Thinopyrum spp], perennial ryegrass [Lolium perenne L.], and other increasingly important species such as switchgrass [Panicum virgatum $L$.]. These grasses reproductive characteristics were described by Poehlman (1987), Hanson and Carnahan (1956), and Carnahan and Hill (1961), and are summarized as follows:

1. The grasses are cross-pollinated by wind in nature and are largely self-incompatible, which restricts the use of breeding systems using self-pollination. For species in which some self-pollination is possible, inbreeding rapidly reduces vigor and reproductive potential. It has not been feasible to develop and maintain inbred lines. 
2. The grasses have small floral parts, making hand emasculation tedious and difficult. Field scale methods of emasculating plants have not been developed. Cytoplasmic male-sterility systems have not been developed except for a few annual, diploid forage grasses.

3. Many of the grasses are polyploids, which complicates inheritance of traits. Most traits are controlled by numerous genes. Few genes have been determined or mapped due to complex inheritance and the inability to self-pollinate plants.

4. Perennial plants can be vegetatively propagated by stolons, rhizomes, tillers, or buds on culms. Individual plants can be replicated and can be subjected to multiple-year evaluations.

5. Individual plants in populations are highly heterozygous. Quantitative genetic studies completed to date indicate substantial additive genetic variation exists in most grasses for most agronomic traits (Vogel et al. 1989; Barker and Kalton 1989; Burton 1989a; and Meyer and Funk 1989).

6. Plants are used in thickly seeded stands or swards as forages or turf grasses. Individual plant selection is not possible under these conditions. Therefore, evaluation and selection is usually done in space-planted nurseries.

\section{BREEDINGSYSTEMS}

The most effective breeding systems for cross-pollinated forage grasses are systems that do not require hand emasculation or crossing, exploit the perennial nature of the plants and their ability to be vegetatively propagated, and which maximize the utilization of additive genetic variation. The breeding systems that meet these requirements are population improvement systems that utilize recurrent selection. The cultivars produced by the recurrent selection systems are improved populations that are released as synthetic varieties. The objectives of the recurrent selection systems are to change population means utilizing additive genetic variation (Fig. 7.1).

The breeding systems that will be discussed are recurrent restricted phenotypic selection (RRPS), conventional half-sib progeny test (HSPT), between and within family selection (B\&WFS), and recurrent multistep family selection (RMFS). Each of these systems is initiated with a base population. Another system that we shall name ecotype selection can be used to assemble, evaluate, select, and intermate germplasm to produce the necessary base populations.

Each system will be discussed using switchgrass as the model plant. 

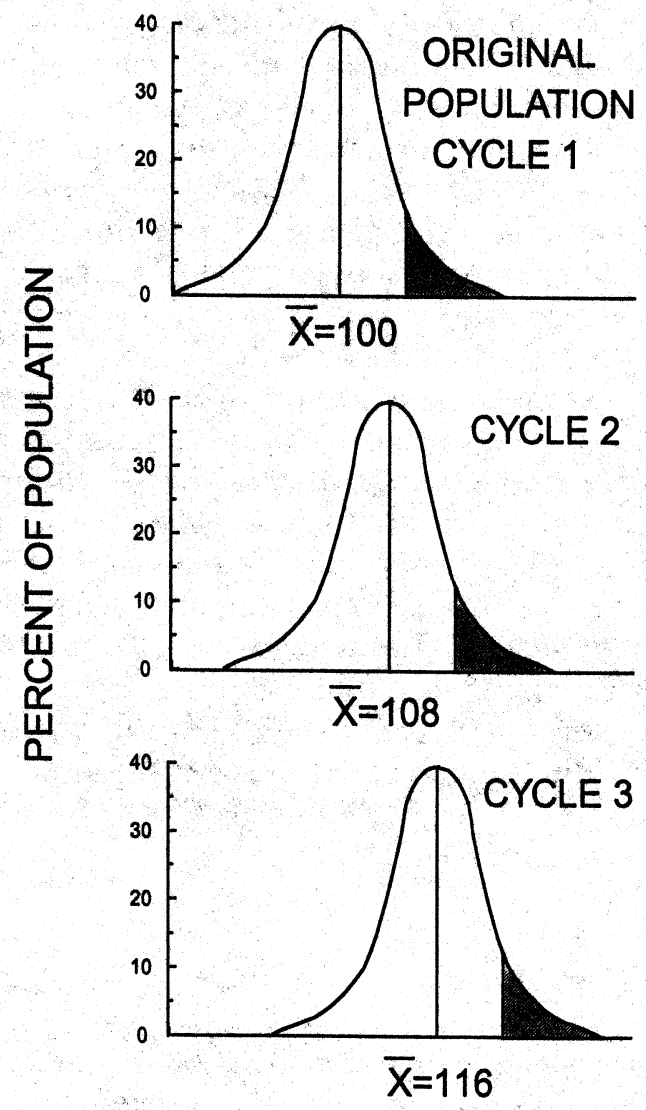

RELATIVE YIELD

Fig. 7.1. Representation of the theoretical effect of three cycles of restricted, recurrent phenotypic selection on yield. The area under the curve represents all the plants in the population. The shaded area represents the selected plants. In this example, $5 \%$ of the highest-yielding plants are selected from each cycle, heritability is $40 \%$ and the phenotypic standard deviation is 10 . The population mean $(\bar{X})$ of the base population (C0) is 100 in cycle 1.

In our environment, ability to survive winters and persist is of paramount importance. Consequently, we establish selection nurseries in year 1 , evaluate the plants in year 2 and/or year 3 , and polycross selected plants the year following evaluation. Plants are not polycrossed until they have survived at least two winters. Each cycle takes 3 or 4 years. This timetable will be used in all subsequent examples. Methods of accelerating this timetable have been developed for specific grasses. Burton $(1974,1982)$ 
has developed methods for completing a cycle a year for Pensacola bahiagrass [Paspalum notatum var. saure Parodi] with RRPS. Methods on decreasing the time period per cycle by manipulating plants are usually not specific to breeding systems, so using the same timetable to compare efficiency of breeding systems is appropriate.

\section{A. Ecotype Selection}

Breeding work on a specific grass is usually initiated to meet an agricultural, turf, or conservation need for a specific region that is not being met by existing grasses or cultivars. If no prior breeding work has been done with a species, it is necessary to collect, assemble, and evaluate germplasm for the specified region. This process, if properly conducted using a system named ecotype selection, can lead to the rapid development and release of excellent cultivars. This breeding system was not developed by any single individual but rather evolved over time.

We will use the development of switchgrass cultivars for the North Central region of the United States as an example. This region (Fig. 7.2) prior to settlement was covered by tallgrass prairie, and switchgrass was one of the dominant grass species. Most of the prairie has been plowed, but remanent prairie sites exist throughout the region from which germplasm can be collected. The genetic variation that existed among plants in the original prairie consisted of the between and within ecotype or endemic strain variability. The genetic variation was created over time by the evolutionary forces of mutation, migration, selection, and random drift or chance (Falconer 1981). The ecotypic or endemic strain variation that exists among grasses collected from specific regions is substantial for both nativeand introduced species (Carnahan and Hill 1961; Dewey 1978).

Ecotype selection is initiated by collecting an array of accessions for the specified region. For native species such as switchgrass, the germplasm is collected from the target region. For introduced grasses, germplasm is collected and assembled from areas of the world that are climatic analogs of the target area. Both native and introduced accessions can be obtained by direct collection or from previous collections stored in germplasm banks. Accessions are usually collected as seed, but in some situations, plants also have been collected and moved to evaluation nurseries. Collecting plants is usually less desirable than collecting seed because it is easier to capture the genetic diversity from a site by randomly collecting seed from cross-pollinated plants than by digging a limited number of plants. Plant collection may be necessary if seed production only occurs sporadically in native sites.

Collecting and bulking seed from many plants at a site is preferable to collecting and maintaining seed collections from individual plants for 


\section{Ecotype or Naturalized Strain Selection}

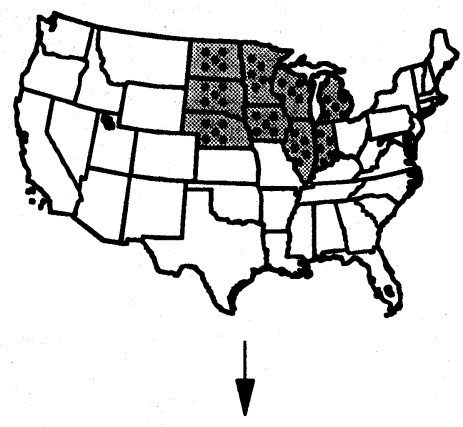

\section{Collection Phase}

Plants or seeds collected from

site in specific geographic

region. * = collection sites.

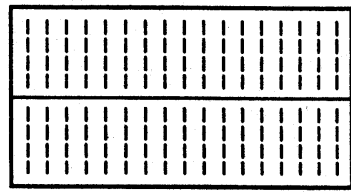

\section{Evaluation Phase}

Collected material evaluated in common evaluation nursery(s).

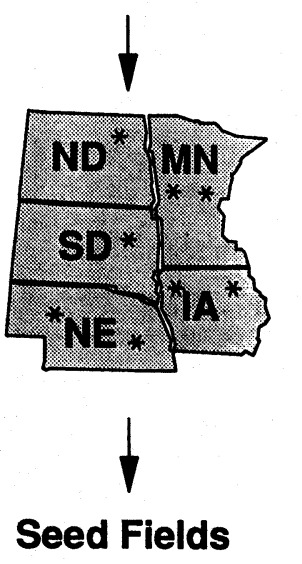

Advanced Testing

"Best" accessions or strains Increased without additional breeding work and evaluated in replicated trials in specific region.

Release

"Best" accession or strain released as a cultivar.

Fig. 7.2. Ecotype or naturalized strain selection. Sites of seed collection are indicated by asterisks $\left({ }^{*}\right)$.

cross-pollinated grasses since the objective is to obtain a representative sample of the genes at a site. Collecting seed from individual, highly heterozygous plants at a site reduces the amount of seed that can be collected and can result in a great deal of unnecessary work in seed processing, cataloguing, evaluation, and maintenance. A possible rationale for collecting seed from individual plants would be the study of genetic variation at the site for specific traits. However, it is possible to 
derive the same information using bulk seed lots in properly designed experiments. In our example, we collect seed in bulk from remanent prairie sites (Fig. 7.2.)

The collected or acquired germplasm is then evaluated in replicated evaluation trials. When many grass breeding programs were initiated in the 1930 s through the 1950 s, these evaluation nurseries were seeded in single-row plots. The more common practice is to start seedlings of the collected seed in greenhouses, which are then transplanted into spaceplanted plots in evaluation nurseries. This is preferred because seed supplies are often limited, collected seed is often of low quality, and accessions may differ significantly in seedling vigor due to production environments at the collection sites. Space-planted evaluation plots give the breeder an opportunity to observe the relative amount of phenotypic variation within accession and to make within accession selections in the original evaluation trials.

The evaluation of the germplasm can be conducted at a single location or multiple locations depending on breeding resources. For a large geographic area, such as the North Central region, multiple evaluation sites would be preferred. In our switchgrass example, we use single-row plots containing 10 plants with $2-4$ replicates per location. Since persistence is essential for perennials, the evaluation trials are conducted for several years. The type of data collected will vary with species and objectives. With switchgrass, the traits of primary interest are forage yield and quality of established plants. Consequently, we collect only minimal data the establishment year and evaluate forage yield and quality in the 2 years following the establishment year.

Data from the evaluation trials are used to select the best ecotypes or accessions. Seed of the best ecotypes can be increased individually without any additional selection for advanced testing in solid seeded (sward) plots in replicated trials. These trials should be conducted at sites throughout the potential area of adaptation. Some of the most productive and widely grown grass cultivars including Kentucky 31 tall fescue, Lincoln bromegrass, and Blackwell switchgrass were developed as direct increases of single accessions (Hanson 1972). When accessions are increased for release without additional selection, only among accession genetic variation is utilized.

When space-transplanted evaluation nurseries are used, phenotypically superior plants can be selected from the best or better accessions to utilize the within accession genetic variation. Superior plants from an accession can be moved to isolated polycross nurseries to produce a population based on a single accession, or superior plants from several accessions can be polycrossed together to produce a new population. Improved populations or strains produced by polycrossing also require testing in replicated trials before release as cultivars. 
The ecotype breeding system and its modifications have been used by state and federal research programs to produce the initial cultivars for most of the perennial cross-pollinated grasses currently being used in the United States. The ecotype breeding system is still being widely used by the Plant Materials Centers of the Soil Conservation Service, U.S. Department of Agriculture to develop cultivars of grasses needed for specific conservation needs.

The ecotype breeding system is also the preferred method to develop random-mating populations for use in breeding systems to be used to produce subsequent generations of improved cultivars. Superior plants from superior accessions can be random mated in polycross nurseries to produce Syn 1 seed of a population. The population should be advanced one or more additional generations of random mating. The resulting population should be suitable for use in the breeding systems described in the following sections. The importance of two or more generations of random mating before initiating breeding work with a synthesized population cannot be overemphasized. The populations should be at random-mating (linkage) equilibrium as defined by Falconer (1981) so that phenotypic differences among plants of a population are due to additive genetic effects rather than heterotic effects. Equations for calculating the potential disequilibrium are given by Falconer (1981).

\section{B. Recurrent Restricted Phentoypic Selection}

Mass selection is the oldest form of plant breeding. It has been used for centuries to develop many of our current crop plants, and it has been adequately described in most plant breeding textbooks. During the past 30 years, major improvements have been made in mass selection as a breeding system. Since these improvements can at minimum double the breeding gain, conventional mass selection generally should not be practiced under most conditions. A possible exception is where a breeder may want to improve the persistence of a particular grass in a unique, stressful environment using very limited resources.

The most efficient form of mass selection as it applies to perennial forage grasses is restricted recurrent phenotypic selection (RRPS) which was developed by Burton $(1974,1982,1992)$. The RRPS method is based in part upon research by C.O. Gardner (1961) who demonstrated that stratifying the selection nurseries into smaller selection units improved realized gains from selection.

The initial step in RRPS is to establish a space-planted evaluation nursery (Fig. 7.3). Greenhouse-grown seedlings are transplanted into a field nursery in year 1. In our example, with RRPS and with the other breeding systems, we will use an initial base population of 1000 and a 
selection intensity of $10 \%$. The plants are allowed to become well established and establishment year data can be collected depending upon the trait of interest. In year 2, the space-planted selection nursery is subdivided into selection units. Burton (1974) subdivided selection nurseries into 40 square 25-plant selection units. The size and shape of the selection unit can be varied. The critical factor is that the selection nursery is subdivided into smaller selection units as means of reducing the impact of environmental variation on selection decisions. In our example, we will subdivide the selection nursery into fifty 20-plant selection units and we measure or evaluate the plants in each selection unit for the desired trait or combination of traits. A fixed number of plants are selected from each selection unit. In our example, our selection

\section{RECURRENT, STRATIFIED, MASS SELECTION (RRPS)}

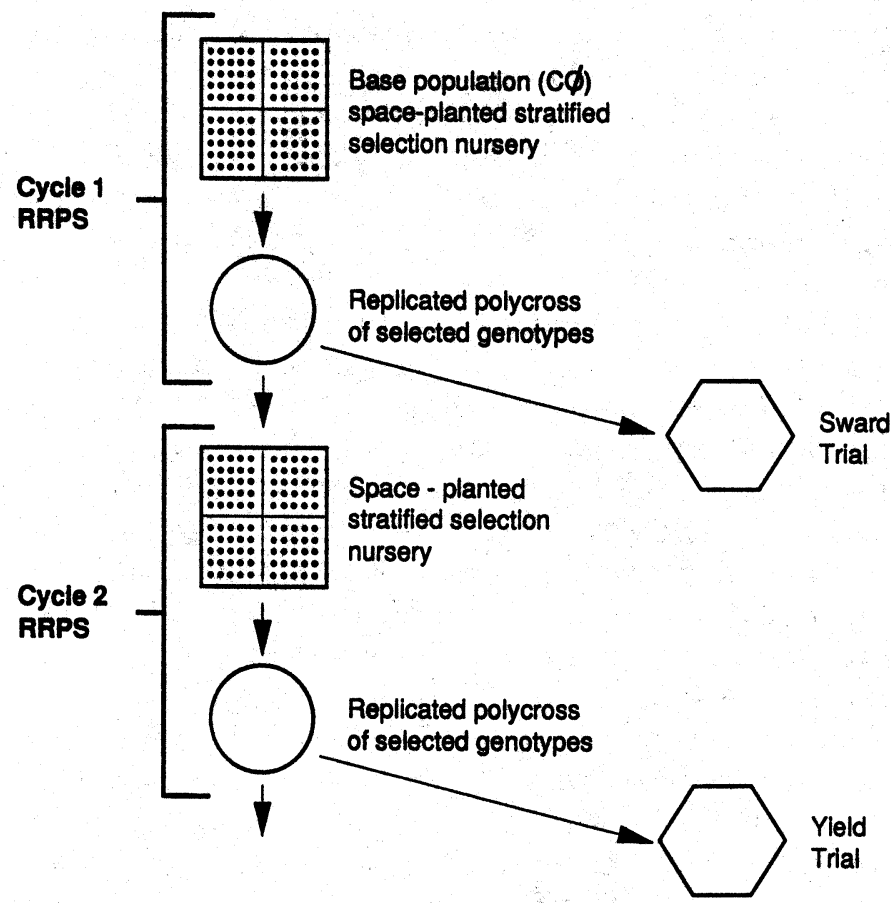

Fig. 7.3. Recurrent, stratified phenotypic selection (RRPS). 
intensity is $10 \%$, so we will select the two best plants from each unit. Another procedure that can be used is adjusting plant values by the deviation of their selection unit means from the overall mean; selection based on adjusted values can be over the entire nursery without regard to selection unit (Shutz and Cockerham 1966).

In year 3, the two best plants from each selection unit are transplanted to an isolated polycross nursery for intermating. If any selected plant fails to survive the winter, the next best plant in each selection unit is selected. Polycrossing selected plants doubles the expected genetic gain from selection as compared with traditional mass selection where only the female parents are selected. In RRPS polycross nurseries, both male and female plants are selected. An equal amount of seed from each plant or genotype in the polycross is bulked and is used to start the next cycle of selection. The polycross nursery is also used to produce seed for yield tests, and it can serve as the source of breeder seed. Intermating in the polycross nursery is a critical feature of each of the breeding systems and is discussed in a separate section.

The next cycle of selection is initiated in year 4 (year 1 of cycle 2) using seed from the previous polycross nursery, and the process is repeated until sufficient genetic gain has been achieved to warrant release of an improved cultivar. We conduct yield tests in solid-seeded sward trials following each cycle of selection.

The advantages of RRPS are that it is an easy breeding system to use, it requires minimum time intervals per cycle, it utilizes all the additive genetic variation, and because of the large number of plants that are intermated, inbreeding depression is minimized (Tables 7.1, 7.2, 7.3). Its disadvantages are that it is not possible to determine the actual rate of inbreeding since pedigree records of individual genotypes and their progenies are not maintained and information on the breeding value of individual genotypes is not available. Although inbreeding rates are theoretically low, in practice, they may be higher because some families may contribute more members to the plants in the polycross nursery than other families. It may also take numerous cycles before sufficient improvements are made to warrant release of an improved cultivar. Burton $s$ (1982) new RRPS method provides a mechanism for maintaining family records, which essentially converts RRPS into a between and within family selection system.

Examples of cultivars produced by RRPS include Tifton 9 bahiagrass, which was released in 1987 after 9 cycles of RRPS that were initiated in 1960 (Burton 1989b). Tifton 9 produced $47 \%$ more forage than the base population over a 3-year period. Trailblazer switchgrass was released following a single cycle of selection for increased dry matter digestibility resulting in $23 \%$ improvement in beef cattle gains per animal and per hectare in a replicated grazing trial (Vogel et al. 1991). 
Table 7.1. Comparison of time requirements for recurrent breeding schemes applicable to cross-pollinated perennial plants

\begin{tabular}{|c|c|c|c|c|}
\hline \multirow[b]{2}{*}{ Activity } & \multicolumn{4}{|c|}{ Time (year) } \\
\hline & $\mathrm{RRPS}^{\mathbf{z}}$ & HSPT & B\&WFS & RMFS \\
\hline Establish source/ selection nursery & 1 & 1 & $1^{y}$ & $1^{\mathrm{y}}$ \\
\hline Evaluation of source/selection nursery & 2 & 2 & $2^{y}$ & $2^{y}$ \\
\hline Polycross selected genotypes & 3 & 3 & $3^{y}$ & $3^{y}$ \\
\hline Replicated progeny test & & $4,5,6^{x}$ & $4,5,6^{\mathrm{xw}}$ & $4,5,6^{x, w}$ \\
\hline Recombine selected plants & & 7 & 7 & $7,7^{\mathrm{v}}$ \\
\hline Initiate cycle 2 & 4 & 8 & 8 & 8 \\
\hline
\end{tabular}

\footnotetext{
${ }^{2}$ Abbreviations defined in figures and text.

${ }^{y}$ These steps needed only to start scheme, expected gain from selection + to RRPS.

${ }^{x}$ One establishment year followed by two evaluation years.

w Families evaluated on a plot basis first evaluation year followed by within family evaluation of best families the following year.

${ }^{v}$ Two separate polycross nurseries must be established.
}

Table 7.2. Expected genetic gain ( $\mathrm{G}$ ) per cycle and per year for recurrent breeding schemes applicable to perennial plants

\begin{tabular}{|c|c|c|}
\hline $\begin{array}{l}\text { Breeding } \\
\text { scheme }^{z}\end{array}$ & Expected genetic gain per cycle ( $(\mathrm{u})^{y, x}$ & $\begin{array}{c}{ }^{-} \text {G year }^{-1} \\
\left(\% \text { of } \sigma_{A}^{2}\right)^{w}\end{array}$ \\
\hline RRPS & $\Delta G=k \sigma_{A}^{2}\left(\sigma_{P S}\right)^{-1}$ & 33.3 \\
\hline HSPT & $\Delta G=k 1 / 2 \sigma_{A}^{2}\left(\sigma_{P F M}\right)^{-1}$ & 7 \\
\hline B\&WFS & $\Delta G=k_{1} 1 / 4 \sigma_{A}^{2}\left(\sigma_{P F M}\right)^{-1}+k_{2} 3 / 4 \sigma_{A}^{2}\left(\sigma_{P W}\right)^{-1}$ & 25 \\
\hline $\begin{array}{l}\text { RMFS } \\
\text { B\&WFS: }\end{array}$ & $\Delta G=k_{1} 1 / 4 \sigma_{A}^{2}\left(\sigma_{P F M}\right)^{-1}+k_{2} 3 / 4 \sigma_{A}^{2}\left(\sigma_{P W}\right)^{-1}$ & 25 \\
\hline HSPT: & $\Delta G=k 1 / 2 \sigma_{A}^{2}\left(\sigma_{P F M}\right)^{-1}$ & J \\
\hline
\end{tabular}

\footnotetext{
${ }^{2}$ Abbreviations defined in figures and text.

${ }^{y} \mathbf{k}=$ standardized selection differential, $\sigma_{A}^{2}=$ additive genetic variance, $\sigma_{P S}=$ phenotypic standard deviation among plants in RRPS selection nursery, $\sigma_{P F M}=$ phenotypic standard deviation among half-sib families on a plot mean basis, $\sigma_{P W}=$ phenotypic standard deviation among plants within selected half- sib families.

×Parental control factors for each scheme is incorporated into equations assuming selected parents are polycrossed in isolation.

${ }^{\text {w }}$ Assuming $\sigma_{P S}=\sigma_{P F M}=\sigma_{P W}$, changes in relative magnitude of these parameters will have relative reciprocal affects on ${ }^{\top} \mathrm{G}$.
} 
Table 7.3, Inbreeding rate ( $\mathrm{F})$ for recurrent breeding schemes applicable to crosspollinated perennial plants

\begin{tabular}{|c|c|c|c|}
\hline $\begin{array}{l}\text { Breeding } \\
\text { scheme }^{z}\end{array}$ & Assumptions & ${ }^{\sim} \mathrm{F}$ cycle $^{-1 y}$ & $F_{n}$ after 5 cycles $^{x}$ \\
\hline RRPS & $\begin{array}{l}1000 \text {-plant-selection nursery, } 10 \% \\
\text { (or } 100 \text { plants) selected for polycrossing }\end{array}$ & 0.005 & 0.03 \\
\hline HSPT & $\begin{array}{l}\text { 1000-plant-source nursery, } 100 \text { plants } \\
\text { selected for polycrossing and progeny } \\
\text { testing, based upon progeny test, } 20 \\
\text { genotypes selected }\end{array}$ & 0.025 & 0.14 \\
\hline B\&WFS & $\begin{array}{l}\text { Space-planted half-sib progeny test has } \\
100 \text { families with } 10 \text { plants per family, } \\
5 \text { best plants of } 20 \text { best families selected } \\
\text { for progeny }\end{array}$ & 0.005 & 0.03 \\
\hline RMFS & $\begin{array}{l}\text { Space-planted half-sib progeny test has } \\
100 \text { families with } 10 \text { plants per family, } \\
5 \text { best plants of } 20 \text { best families selected } \\
\text { for progeny }\end{array}$ & 0.005 & 0.03 \\
\hline
\end{tabular}

${ }^{z}$ Abbreviations defined in figures and text.

y $\mathrm{F}=1 /(2 \mathrm{~N})$ where $\mathrm{N}=$ effective population size (Falconer 1981).

${ }^{x} F_{n}=1-P n$ (panmictic index) when $P n=P_{1}(1-1 / 2 N)$ (Kempthorne 1957).

\section{Half-sib Progeny Test}

Half-sib progeny tests (HSPT) have probably been the most widely and extensively used grass breeding method. This system has been useful for developing initial cultivars but has not been successful for subsequently improving traits, such as forage yield. We believe that the lack of progress with traits such as yield can be attributed to one or both of the following reasons: (1) the system is theoretically less than half as efficient as other systems and (2) because breeders have also sabotaged themselves by using base populations that were not in linkage equilibrium.

If conducted properly, HSPT is initiated by establishing a spaceplanted source nursery of a random mated population that is in linkage equilibrium (Fig. 7.4). The procedures for handling the space-planted source nursery are identical to cycle 1 (C1) of RRPS. Approximately $10 \%$ of the better plants are selected for transplanting to a isolated polycross nursery. Seed is harvested from individual plants in the polycross nursery and bulked by genotype. Since this stage of the process is identical to C1 of RRPS, this portion of the process would take 3 years using our model. Progeny from each genotype are then established in a replicated half-sib progeny evaluation nursery or nurseries. These nurseries can be solid-seeded plots or single row, space-planted plots. One year is required for establishment, and the families are evaluated for 2 
subsequent years. Data from the half-sib families are then used to select a subset of superior genotypes from the original polycross nursery (Fig. 7.4). This subset of genotypes (usually 20 or less) is then random mated in a polycross to produce seed for testing in replicated yield tests at multiple sites and can also be used as a potential breeder seed field.

HSPT is usually stopped after a single cycle. The reason for this is that repeating the process would simply involve reevaluation of the same clones that were evaluated in the previous cycle except that the clones would be mated to a smaller number of male parents. It either leads to an improved cultivar at the end of a single cycle or it does not. It only utilizes

\section{CONVENTIONAL HALF-SIB PROGENY TEST (HSPT)}

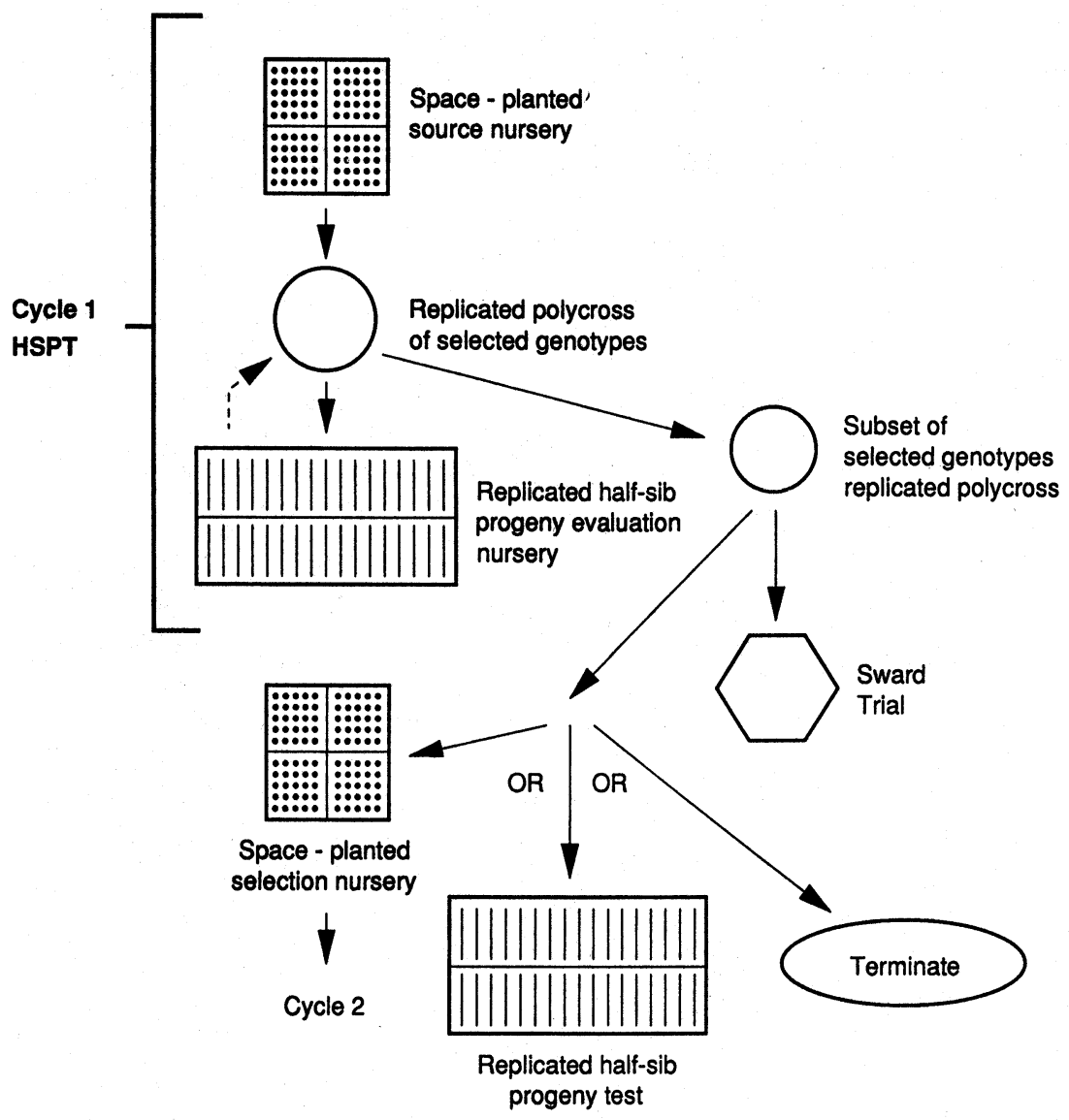

Fig. 7.4. Conventional half-sib progeny test (HSPT) 
the among family genetic variance, which results in only $1 / 2$ of the total additive variance being utilized (Table 7.2) so it is inherently inefficient. It is the least efficient breeding system that a breeder can use to improve perennial, cross-pollinated forage grasses in a sustained, recurrent breeding program.

Grass breeders have previously used various arrays of germplasms to establish source nurseries and have often included plants from older cultivars, plant introductions, or other germplasm stocks. Breeders evaluated the plants in the source nursery and selected the best plants to include in the polycross nursery. Progeny from the polycross were evaluated in a replicated half-sib progeny test. Because parent plants in the polycross nursery came from various germplasm sources and were not in linkage equilibrium, it is highly probable that half-sib progeny differences were due to differing levels of heterosis. Progeny data thus would not reflect breeding values of the parents. It is our contention that failures to improve forage yields of grasses by using conventional half-sib progeny tests were due to parents being selected from source nurseries that were not in HardyWeinberg or linkage equilibrium. This contention is difficult to document because negative results are usually not published.

\section{Between and Within Family Selection}

Between and within family selection (B\&WFS) is a breeding system that utilizes both the among and within family additive genetic variation. This breeding system is also initiated by establishing a space-planted source nursery that is used to identify superior phenotypes whose progeny will be evaluated in subsequent trials (Fig. 7.5). The source nursery should be a random-mated population in linkage equilibrium. The most efficient system for identifying superior phenotypes from this type of source nursery is RRPS. Using our switchgrass model, the first 3 years of this procedure would be the same as cycle 1 of RRPS. A 1000 plant selection nursery is established and 100 genotypes are selected for intermating in the polycross nursery. An equal number of seed is harvested from each plant in the cycle 1 polycross nursery and bulked by female genotypes. These seed lots are then used to establish a replicated space-planted half-sib progeny evaluation nursery. Although we will consider only a single location, evaluation nurseries could be established at several locations.

To keep the number of plants in selection nurseries consistent over breeding systems so that we can make comparisons among them, our B\&WFS progeny selection nurseries will contain 2 replicates of 100 families with 5 plants per family each per replication. Plots are single rows of spaced plants. Although a randomized complete block design 
could be used, we recommend the use of a design such as a reps-in-block design to reduce field variation (Schutz and Cockerham 1966). We stratify or subdivide the progeny evaluation nursery into 10 blocks, randomly assign 10 of the selected families to each of the blocks, and then independently randomize families within each block as though each block was a small randomized, complete block experiment.

In our model with switchgrass, year 1 of the progeny evaluation is used for establishment of the nursery; year 2 is then used to evaluate families on a plot basis, year 3 is used to identify the best plants within the best families, and in year 4 , the selected plants are moved to isolated

\section{RECURRENT BETWEEN AND WITHIN HALF-SIB FAMILY SELECTION (B \& W FS)}

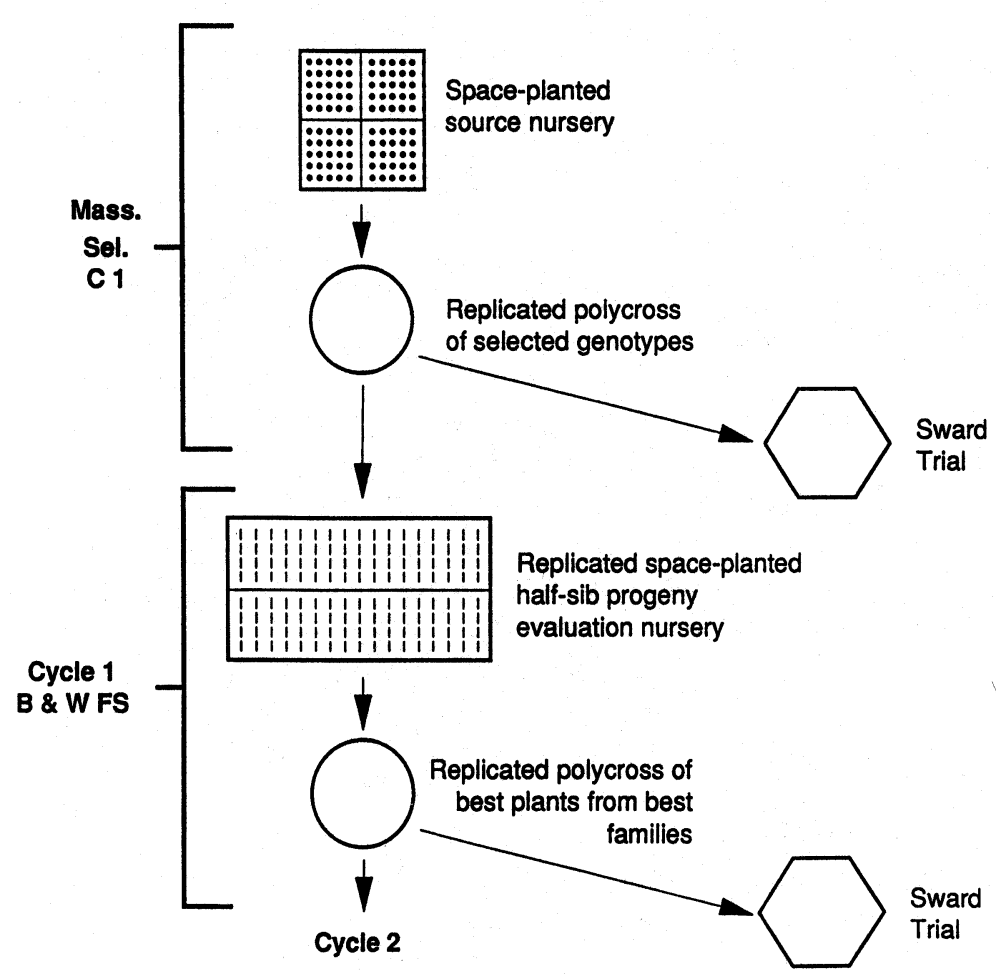

Fig. 7.5. Recurrent between and within half-sib family selection (B\&WFS) 
nurseries and polycrossed. It would be possible to conduct the family and individual plant evaluations in a single year. However, much of our breeding work is for forage yield and quality. Conducting both among and within family selection in the same year would require us to harvest and conduct quality tests on 1000 plants. By doing the evaluation work in stages, we reduce the harvesting and laboratory workload by $50 \%$. In year 1 we harvest 200 family plots and in year 2 we harvest a total of 200 individual plants ( 20 families with 10 plants per family) for a total of 400 plots or plants harvested and analyzed. Although it takes an additional year to complete a cycle, the savings in resources can be used to conduct breeding work on other populations.

If a randomized complete block design is used, the 5 best plants from the 20 best families in the nursery would be selected ( 100 plants) and moved to an area of isolation for polycrossing. If a reps-in-block design is used, the two best families within each individual field block would be selected. The five best plants within each of these families would be selected for polycrossing to start the next cycle of selection. Use of the reps-in-block design stratifies the half-sib family selection nursery into smaller selection units, which should reduce environment variation and increase selection efficiency. If possible, an equal number of plants should be selected from each family plot. Since in our model, we want to select 5 plants per family, we would select 3 plants from 1 replicate and 2 from another replicate. Again, seed from the polycross nursery can be used to start another cycle of selection and produce seed for testing and increase.

This breeding system has several major advantages over the conventional half-sib family progeny test. By selecting plants from within families, it is possible to maintain adequate population size, which reduces inbreeding (Table 7.3). Since recombination occurs in each polycross nursery, recurrent cycles of selection can be effectively utilized, and expected gains from selection are considerably greater (Table 7.2). In comparison to RRPS, the expected gains from selection are comparable if among and within family evaluations are all completed the same year, and assuming that phenotypic variances among plants and families in the selection nurseries are similar. If family and within family evaluations are completed in separate years for B\&WFS, then RRPS would be more efficient. However, if heritabilities of desired traits are low, the phenotypic standard deviation of the plants in the RRPS selection nursery could be greater than the phenotypic standard deviation among half-sib families on a plot mean basis or the phenotypic standard deviation among plants within selected half-sib families, which would make B\&WFS more efficient. Since family records are maintained, the rate of inbreeding can also be monitored.

Aastveit and Aastveit (1990) reported in a genetic study with meadow 
fescue (Festuca pratensis Huds.) that the additive variation for yield was about three times greater within half-sib families as among families meeting theoretical expectations. They also reported that the estimated gain from selection for their population was greater for between and within half-sib family selection than selection among replicated clones or families. They also proposed a modification of between and within half-sib family selection in which parent and progeny clones are grown in the same nursery. This would provide information similar to that obtained for recurrent multistep family selection (below) but would require more field work.

\section{E. RecurrentMultistep Family Selection}

Recurrent multistep family selection (RMFS) is a modification of between and within family selection, which we are currently evaluating. It is conducted exactly the same as B\&WFS except the polycross nursery that is used to produce seed for a subsequent half-sib progeny evaluation nursery is maintained until that evaluation is complete (Fig. 7.6). The information from the among and within half-sib family evaluation nursery is used: (1) to select in the progeny nursery the best plants from the best families for polycrossing exactly as in the B\&WFS system and (2) to select a subset of superior genotypes from the parent polycross nursery using the means obtained from their replicated progeny. The subset of superior genotypes from the parent polycross nursery are then moved to a separate polycross nursery. Once initiated, each cycle of selection produces two populations for testing, an elite population based on progeny-tested genotypes, and a broader-based population that can be used to capture the gains of the previous cycles of selection and to continue the recurrent selection process.

RMFS has all the advantages of B\&WFS and in addition permits the identification of elite genotypes that can be used to produce synthetic cultivars or possibly population hybrid cultivars by intermating selected genotypes from several populations. Potential gain from selection may be greater than RRPS if the gain from selection of superior genotypes in the parent polycross nursery is added to the gain achieved when the genotypes in the polycross nursery were identified in the previous cycle of selection (Fig. 7.6, Table 7.2). We are currently evaluating this breeding system for both cool- and warm-season grasses but to date no data is available to compare actual and theoretical gains. The data obtained from this breeding system also enables a breeder to obtain estimates of genetic variances by using variance component analyses and parent-progeny regression. This enables a breeder to monitor the additive genetic variation in a population for each cycle of selection and the rate of inbreeding. 


\section{RECURRENT, MULTISTEP, BETWEEN AND WITHIN HALF-SIB FAMILY SELECTION (RMFS)}

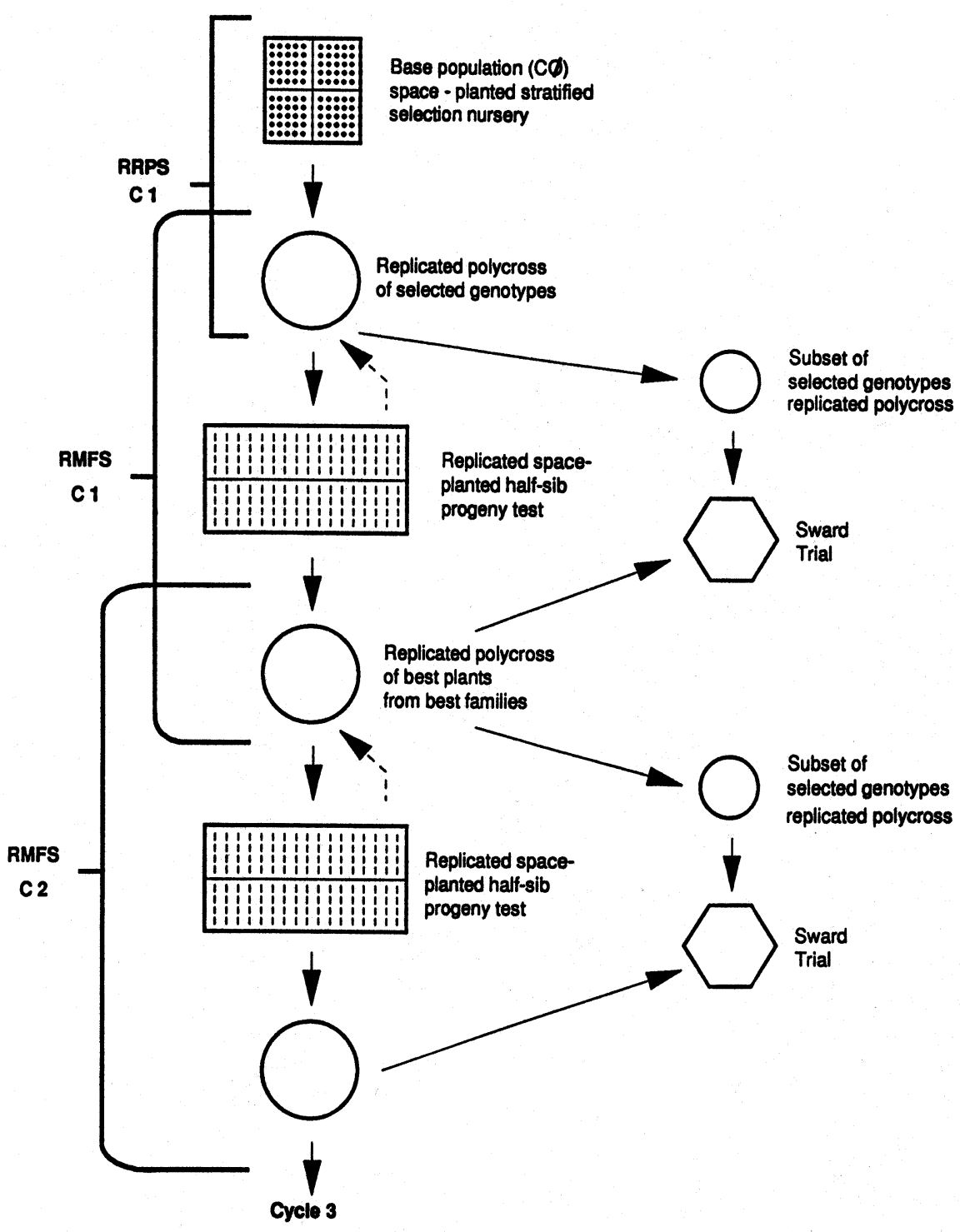

Fig. 7.6. Recurrent, multistep, between, and within half-sib family selection (RMFS). 


\section{IV.GAINS FROMSELECTION}

\section{A. Time Interval per Cycle}

The time interval per cycle is one of the primary factors determining the efficiency of a breeding system. The time per cycle for each of the systems that we have discussed is summarized in Table 7.1. The family selection systems take an additional year per cycle if separate years are used to evaluate families and plants within families. If among and within family evaluation are all completed the same year, the time duration per cycle would be the same as for RRPS. In his RRPS system for Pensacola bahiagrass, Burton $(1974,1982)$ can compete a cycle a year. A cycle a year could also be completed in bahiagrass for B\&WFS and RMFS if the same plant handling procedures are imposed. The number of years per cycle is more dependent upon the unique characteristics of a grass, the breeders ability to manipulate the plant characteristics, and the personnel and financial resources available to the breeder than on the breeding system per cycle. There may be disadvantages to advancing too rapidly in a breeding program. Recently, in one of our switchgrass populations being selected for high in vitro dry matter digestibility, over $90 \%$ of the plants in the selection nursery winter killed during the establishment year. If we had been conducting a cycle a year, we could have continued several cycles of selection without realizing that we had a winter survival problem.

\section{B. Potential Gain per Cycle}

The potential gain per cycle for recurrent selection breeding systems is dependent on the genetic variation in the population, the heritability of the trait, the intensity of selection, and the efficiency of the mating or polycrossing portion of the system (Falconer 1981; Empig et al. 1972; Nyquist 1991; Hallauer and Miranda 1981; Nguyen and Sleper 1983). In determining the expected rate of gain per cycle and per year (Table 7.2), the expected rates of gain equations that were reported by the previous authors were adapted to the breeding systems described for crosspollinated perennial grasses. The expected rates of gain are expressed in terms of additive genetic variance. In all breeding systems, it was assumed that selected clones would be intermated in isolated polycross nurseries. Conventional half-sib progeny testing, which for many years was a widely used breeding system, is by far the least efficient breeding system. Between and within family selection and RMFS would be as efficient as RRPS if family and within family evaluations were all completed the same year. 


\section{C.Potential Inbreeding per Cycle}

Inbreeding can decrease yields of cross-pollinated grasses. Virtually any form of recurrent selection will result in some inbreeding since the objective of the procedures is to increase the frequency of desired alleles. The rate of inbreeding should be kept at a low level so that breeding gains are not offset or reduced by inbreeding depression. The expected rates of inbreeding for the breeding systems that we have described (Table 7.3) indicate that inbreeding depression would only be a problem with conventional half-sib progeny testing if it was used as a recurrent selection breeding system.

\section{V.POLYCROSSING}

In each of the breeding systems described previously, the selected plants are intermated in isolated polycross nurseries. According to Fehr (1987) the polycross concept was apparently developed independently by H.N. Frandsen and by H.M. Tysdal and his coworkers at Nebraska. The purpose of the polycross is to randomly intermate selected plants to produce progenies for the next cycle of selection, fix the gains made in the last cycle of selection, and to begin the seed increase process for evaluation and possibly subsequent release. Allard s (1960) succinct definition of polycross is open pollination of a group of genotypes (generally selected) in isolation from other compatible genotypes in such a way as to promote random mating inter se. It is essentially a top-cross in which selected plants are intermated (Sleper 1987).

The two critical aspects of polycrossing selected plants are isolation and random mating. Isolation is essential so that only selected plants mate with selected plants. Isolation can be achieved by physically moving the selected plants to either field or greenhouse isolations or by bagging the inflorescences of the plants and intermating the plants using collected pollen.

The method can be modified so that it is the most efficient and economical with individual species. In bahiagrass, Burton (1974) collects culms and attached roots from selected plants just prior to flowering and places them in plastic jugs filled with water. All of the collected culms are covered with a large paper tent. The tent and plants are shaken daily to distribute pollen within the bag. The excised culms produce the polycrossed seed. Asay (1992, personal communication) bags spikes on individual crested wheatgrass plants, collects and mixes pollen from all selected plants, and completes the polycrossing by fertilizing the bagged spikes with the collected pollen. In switchgrass, we dig up ramets of 
selected plants and move these ramets to isolated polycross nurseries. We use this procedure because we cannot get the quantity of seed needed for early generation testing using the other procedures and because of the difficulty of keeping bags on plants in our windy environment.

According to the Hardy-Weinberg law, allele frequencies in a population can be fixed by a single cycle of random mating in the absence of selection, nonrandom mating, differential migration, or differential mutation (Allard 1960). A single cycle of random mating of selected plants in a polycross nursery can fix the gene frequencies and thus fix the genetic gains that have been achieved by selection. Two principal problem areas are nonrandom mating and selection because of intentionally or inadvertently allowing some of the genotypes to have more than their equivalent progeny (seed) in the next generation. The latter inadvertent selection problem can be resolved by using the same amount of seed from each genotype.

Random mating exists when each individual in the population has an equal opportunity to be mated with any other individual in the population. Nonrandomness of mating can be due to nonsynchronization of flowering, unequal pollen production, and position effects in the nursery. The flowering periods of the clones included in the polycross should be known, and plants with differing flowering dates should not be included in a polycross unless the breeder is intentionally attempting to broaden the area of adaptation of a cultivar. Plants that are adjacent to each other are more likely to intermate under wind-pollinated conditions than those that are further apart (Fehr 1987). Knowles (1969) has documented that nonrandom pollination can occur in bromegrass polycrosses. Because all plants cannot be adjacent to each other, the problem can be solved be dividing selected plants into clonal pieces or ramets and replicating the genotypes in the polycross nursery by using a randomized complete block, Latin square, or completely randomized design. The critical aspect of setting up the polycross is the random assignment of selected plants to their position in the polycross nursery. Methods for systematically arranging plants in a polycross (Olesen and Olesen 1973) have been developed, but they appear to violate the requirements of random assignment of plants in the polycross. Unequal pollen production can be alleviated by bagging inflorescences, collecting and mixing equal amounts of pollen from each plant, and transferring pollen by hand to bagged inflorescences.

In virtually all plant breeding textbooks (Allard 1960; Fehr 1987) the sections on synthetic varieties present an equation (see below) derived by Sewell Wright in 1922, which estimates the performance of a synthetic.

$$
F_{2}=\bar{F}_{1}-\bar{P} / n
$$


$\mathrm{F}_{2}$ is the predicted performance of the synthetic, $\bar{F}_{1}$ is the mean performance of all possible single crosses among the $n$ plants in the synthetic and $\bar{P}$ is the mean performance of the parents (Fehr 1987). This equation, however, is simply not used in practice to establish synthetics. It is too costly in terms of time and money to obtain the $F_{1}$ data. Currently, breeders are using either data on the individual plants or their polycrossed progeny to select plants for inclusion in synthetics.

\section{HYBRIDCULTIVARS}

Hybrids for commercial use have not been developed for most perennial forage grasses except those capable of large-scale vegetative propagation because of the inability to effectively emasculate large numbers of plants in seed production fields. This has prevented breeders from capitalizing on heterotic effects that are present in many grasses for traits such as forage yield. Summaries of possible methods to produce hybrids of forage grasses have been reported recently by Burton (1986) and Vogel et al.(1989). These methods include first generation chance hybrids, selfincompatibility hybrids, cytoplasmic male-sterile hybrids, apomictic hybrids, and hybrids produced by the use of male-gametocides. To date, first-generation chance hybrids and apomictic hybrids have been produced for a limited number of grasses. Hybrids currently are not a feasible method for producing cultivars of most cross-pollinated grasses. However, advances in science and technology could result in developments that would make hybrid cultivars economically practical. Production of hybrids depends on both the system for producing hybrids and suitable plants from heterotic groups. Consequently, in the USDA-ARS grassbreeding program at the University of Nebraska, we are conducting population improvement breeding work on several populations of each of the grasses that we are attempting to improve. Superior clones from the separate populations could be used to produce hybrids by some of the procedures listed previously or by new hybridization procedures. Populations also could be intermated resulting in a population with increased genetic variation for desired traits.

\section{VII.CONCLUSIONS}

Genetic gains that can be made in a breeding program in a single generation in perennial, cross-pollinated grasses for economically important traits are often small. Long-term, multigeneration or recurrent breeding programs are necessary to accumulate and fix significant improvements by breeding. Although perennial forage grasses have some 
reproductive characteristics that limit the breeding systems that can be utilized in their improvement, some very effective and efficient breeding systems are available for use on these grasses. These systems include restricted recurrent phenotypic mass selection (RRPS) and among and within family selection breeding systems (B\&WFS and RMFS).

RRPS, B\&WFS, and RMFS systems are more efficient and effective on perennial grasses than they are on annual grain crops because of the perennial nature of the grasses and because they can be vegetatively cloned. These systems are currently the most efficient breeding systems that are available for use by breeders of perennial, cross-pollinated grasses. Their superiority over other systems should essentially make systems such as conventional mass selection and conventional half-sib progeny testing obsolete. These older systems were effective in developing the first cultivar of a species for specific geographic regions but they simply do not have the breeding power to make significant improvements over existing cultivars in reasonable periods of time. The ecotype selection system should be an integral part of grass breeding programs because it is a very efficient method of evaluating and integrating new germplasm into a breeding program.

It is likely that improvements in breeding systems for grasses will be developed. Methods of emasculating grass plants on a large-scale basis would permit the use of hybrid breeding procedures. Molecular genetic breeding procedures will be utilized to improve forage grasses. Incorporating molecular genetic improvement procedures into cultivar development programs will be challenging for grass breeders but will provide opportunities to make major improvements in specific traits such as disease and insect resistance or tolerance.

\section{LITERATURECITED}

Aastveit, A.H., and K. Aastveit. 1990. Theory and application of open-pollination and polycross in forage grass breeding. Theor. Appl. Genet. 79:618-624.

Allard, R.W. 1960. Principles of plant breeding. Wiley, New York.

Asay, K.H., Rod V. Frakes, and Robert C. Buckner. 1979. Breeding and cultivars. p. 111-139. In: Robert C. Buckner and Lowell P. Bush (eds.), Tall Fescue. Agronomy Monograph 20. ASA-CSSA-SSSA. Madison, WI.

Barker, R.E., and R.R. Kalton. 1989. Cool-season forage grass breeding: progress, potentials, and benefits. p. 5-20.In:D.A. Sleper, K.H. Asay, and J.F. Pedersen (eds.), Contributions from Breeding Forage and Turf Grasses. Crop Science Special Publication Number 15. Crop Science Society of America, Madison, WI.

Bashaw, E.C., and C. Reed Funk. 1987. Apomictic grasses. pp. 40-82. In: Walter R. Fehr. (ed.), Principles of Cultivar Improvement. Macmillan, New York.

Burson, B.L. 1980. Warm-seasongrasses. p. 695-708. In:W.R. Fehrand H.H. Hadley (eds.), Hybridization of Crop Plants. Am. Soc. of Agron. Crop Sci. Soc. of Am., Madison, WI.

Burton, Glenn W. 1974. Recurrent restricted phenotypic selection increases forage yields of Pensacola bahiagrass. Crop Sci. 14:831-835. 
Burton, Glenn W. 1982. Improved recurrent restricted phenotypic selection improves Bahia forage yields. CropSci. 22:1058-1061.

Burton, Glenn W. 1986. Developing better forages for the south. J. Anim. Sci, 63:63-65.

Burton, Glenn W., 1989a. Progress and benefits to humanity from breeding warm-season forage grasses. p. 21 - 29.In:D.A. Sleper, K.H. Asay, and J.F. Pedersen (eds.), Contributions from Breeding Forage and TurfGrasses. Crop Science Special Pub. 15. Crop Society of America. Madison, WI.

Burton, Glenn W., 1989b. Registration of Tifton 9 pensacolabahiagrass.Crop Sci. 29:1326.

Burton, Glenn W. 1992. Recurrent Restricted Phenotypic Selection. Plant Breed. Rev. 9:101-113.

Carnahan, H.L., and Helen D. Hill. 1961. Cytology and genetics of forage grasses. Bot. Rev. 27:1-162.

Dewey, Douglas R,, 1978. Intermediate wheatgrasses of Iran. Crop Sci. 18:43-48.

Empig, L.T., C.O. Gardner, and W.A. Compton. 1972. Theoretical gains for different population improvement procedures. Nebraska Agr. Expt. Sta. Bul. Misc. Pub. 26 (revised).

Falconer, D.S. 1981. Introduction to Quantitative Genetics 2nd ed. Longman, New York. Fehr, Walter R. 1987. Principles of Cultivar Development. Vol 1. Macmillan, New York.

Gardner,C.O. 1961. An evaluation of effects of mass selection and seed irradiation with thermal neutrons on yields of corn. Crop Sci. 1:241-245.

Hallauer, Arnel R., and J.B. Miranda, Fo. 1981. Quantitative Genetics in Maize Breeding. Iowa State Univ. Press. Ames, IA.

Hanna, W.W., and E.C.Bashaw. 1987. Apoxmis:Its identification and use in plant breeding. CropSci. 27:1136-1139.

Hanson, A.A. 1972. Grass varieties in the United States. USDA Agri. Hand. 170. U.S. Government Printing Office, Washington,D.C.

Hanson, A.A., and H.L. Carnahan. 1956. Breeding perennial forage grasses. USDA Tech. Bul. 1145. Washington, D.C.

Hovin, A.W. 1980. Cool-season grasses. p. 285-298. In: W.R. Fehrand H.H. Hadley (eds.), Hybridization of Crop Plants. Am. Soc. of Agron. Crop Sci. Soc. of Am., Madison, WI.

Knowles, R.P. 1969. Non-random pollination in polycrosses of smooth bromegrass. Crop Sci.9:58-61.

Kempthorne, Oscar. 1957 An Introduction to Genetic Statistics. John Wiley, New York.

Meyer, William A., and C. Reed Funk. 1989. Progress and benefits to humanity from breeding cool-season grasses for turf. p.31-48. m:D.A.Sleper,K.H.Asay, andJ.F.Pedersen (eds.), Contributions from Breeding Forageand Turfgrasses. Crop Science Special Publ. 15. Crop Science Society of America, Madison, WI.

Nguyen, H.T., andD.A. Sleper. 1983. Theory and application of half-sib matings in forage grass breeding. Theor. Appl.Genet. 64:187-196.

Nyquist, Wyman E. 1991. Estimation of heritability and prediction of selection response in plant populations. Crit. Rev. Plant Sci. 10:235-322.

Olesen, Knud, and Olesen, O.J. 1973. A polycross pattern formula. Euphytica 22:500-502.

Poehlman, J.M. 1987. Breeding field crops 3rd ed. AVI, Westport, Conn.

Schutz,W.M. and C.C. Cockerham. 1966. The effect of field blocking on gain from selection. Biometrics 22:843-846.

Sleper, David A. 1987. Forage Grasses, p.161-208. In: Walter R. Fehr. (ed.), Principles of Cultivar Improvement. Macmillan, New York.

Vogel,K.P.,H.J.Gorz, andF.A. Haskins. 1989. Breeding grasses for the future. p. 105-122. In: D.A.Sleper, K.H. Asay, and J.F.Pedersen (ed.)Contributions from Breeding Forage and Turf Grasses. Crop Science Special Publ. 15. Crop Science Society of America, Madison, WI.

Vogel, K.P., F.A. Haskins, H.J. Gorz, B.A. Anderson, and J.K. Ward. 1991. Registration of Trailblazer switchgrass. Crop Sci. 31:1388.

Wilkins,P.W. 1991. Breeding perennial ryegrass for agriculture. Euphytica 52:201-214. 